\title{
Online Crowdfunding Response to Coronavirus Disease 2019
}

$\mathrm{J}$ Gen Intern Med 35(8):2482-4

DOI: $10.1007 / \mathrm{s} 11606-020-05896-\mathrm{x}$

(c) Society of General Internal Medicine 2020

\section{INTRODUCTION}

By early March 2020, the coronavirus disease (COVID-19) pandemic shocked and overwhelmed government and public health organizations across the world. In response, unprecedented isolation and public health measures have been deployed, as well as efforts to mitigate the economic impacts of this crisis. ${ }^{1,2}$ Online crowdfunding, because of its accessibility and outreach, has in recent years become a powerful tool to help finance medical treatment and research. ${ }^{3}$ As the world confronts the COVID-19 pandemic, online crowdfunding provides a dynamic opportunity to understand relief needs locally and public responses globally, which may reveal areas for improved coordination and preparedness. This study aims to characterize early fundraising associated with COVID-19 on GoFundMe.com, the largest-by-volume online crowdfunding platform.

\section{METHODS}

We designed and implemented a custom web scraping tool to extract campaign data on GoFundMe.com. The software was constructed in a Python environment using the Selenium (www.selenium.dev) software testing framework and Scrapy (www.scrapy.org) open-source framework in tandem to navigate the website architecture. We extracted data for active campaigns using the keywords relevant to COVID-19 pandemic and characterized campaigns that emerged March 3-20, 2020, the period which coincided with an inflection point in both mortality and incidence outside of China. ${ }^{4}$ We compiled the date, time, and origin of identified campaigns. We generated a random sample of 200 campaigns and manually verified the needs articulated relating to the number of donors, goal fundraising amount, country of origin, and language. Among the subset of campaigns dedicated to medical supplies, we further characterized the need for personal protective equipment (PPE), intensive care devices

Received April 9, 2020

Accepted April 30, 2020

Published online May 27, 2020 including ventilators, and testing equipment. We compared reported funding needs between campaigns originating in the United States (U.S.) and non-U.S. countries.

\section{RESULTS}

We identified 1579 campaigns that were created on GoFundMe.com for the COVID-19 pandemic between March 3 and 20,2020, with a total fundraising goal of $\$ 1,492,988,587$. The number of active campaigns rapidly increased with the spread of COVID-19 (Fig. 1). The median fundraising goals was $\$ 10,000$ per campaign (interquartile range, $\$ 4320-27,000$ ), and the median amount raised by March 20, 2020, was $\$ 1642$ (interquartile range, \$578-5005) per campaign over a median duration of 7 (interquartile range, 4-11) days. In the U.S., most campaigns fundraised for living expenses, lost wages, and food (88.0\%), while a minority fundraised for medical supplies $(8.7 \%)$ or for hospitals and healthcare workers $(3.3 \%)$ (Table 1$)$. In contrast, non-U.S. campaigns ( $82.4 \%$ directed at Italy) focused on hospitals and healthcare workers $(54.6 \%)$ or medical supplies $(26.9 \%)$, while a minority requested funds for living expenses, lost wages, and food $(16.7 \%)$ or research (1.9\%) (Table 1).

\section{DISCUSSION}

There was a robust online crowdfunding response to the COVID-19 pandemic, with the pattern of campaigns paralleling the paralleling the awareness and detection of the disease. Although the initial emphasis of U.S. crowdfunding was centered on defraying economic losses, a comparison of campaigns between the U.S. and Europe reveals potential challenges and opportunities that might lay ahead. In the early phase of this pandemic, Italy became the unfortunate bellwether of a disease that outpaced local resources. ${ }^{5}$ As COVID-19 mitigation strategies around the world aim to limit exhaustion of healthcare systems, strain on medical services and resources such as protective equipment has already become apparent. Therefore, our findings support greater prospective rather than retrospective urgency for reinforcing healthcare systems given that their collapse may overtake shortterm economic considerations. ${ }^{6}$ 


\section{Online Crowdfunding Associated with the COVID-19 pandemic}

1800

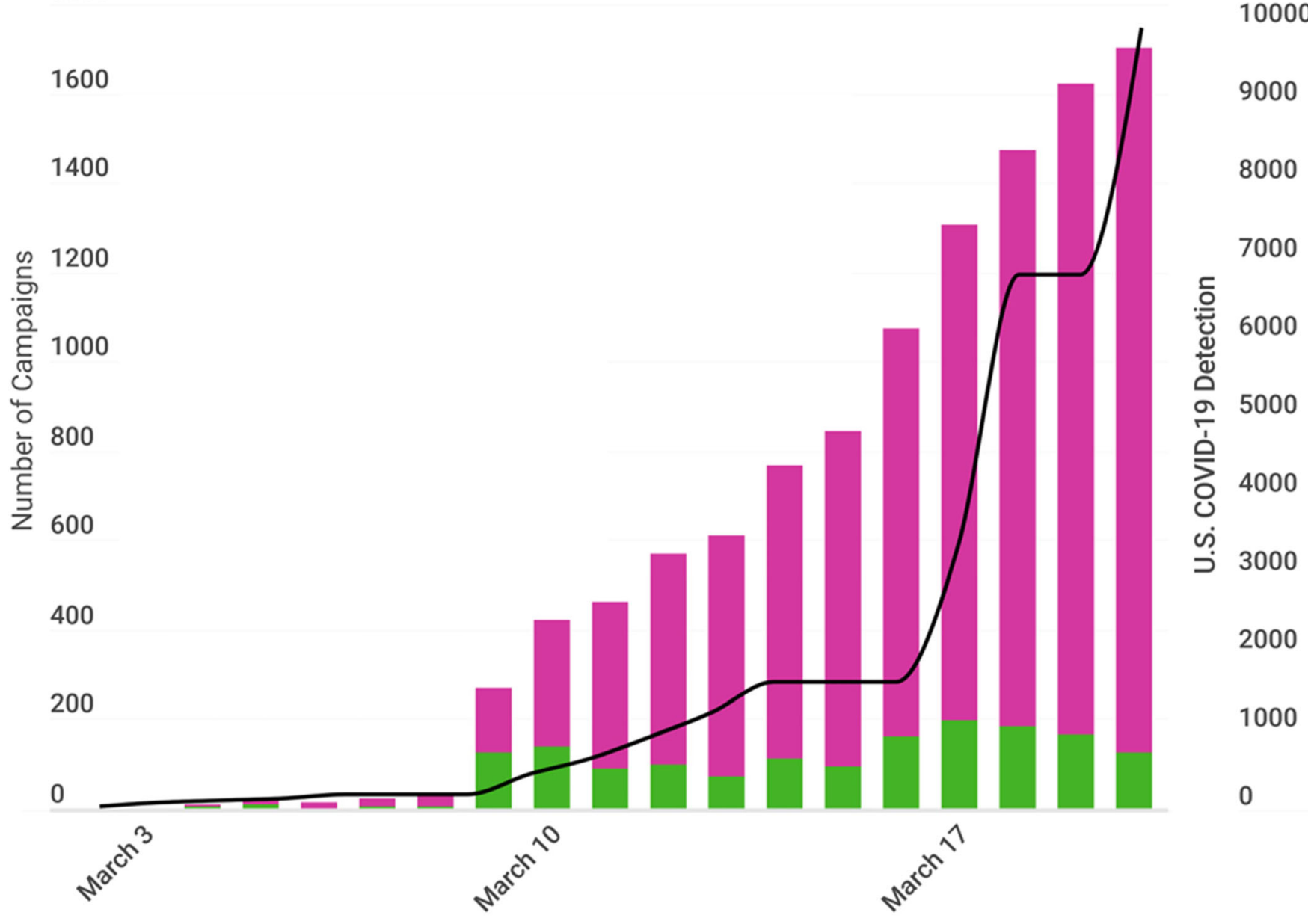

Daily New Campaigns Total GoFundMe Campaigns

Figure 1 Number of GoFundMe.com Crowdfunding campaigns (bar) for COVID-19 and reported U.S. incidence the disease through March 20, 2020 (line) in March 2020.

A limitation of our study was that we extracted campaign data at a single time point and only captured a sample, albeit likely representative, of online crowdfunding campaigns.
Taken together, this study highlights the responsiveness of online crowdfunding during public health emergencies and implies critical opportunities to augment relief efforts, while 
Table 1 Characteristics of 200 Randomly Selected GoFundMe.com Crowdfunding Campaigns for Coronavirus Disease 2019 in March 2020

\begin{tabular}{ll}
\hline \hline All randomly selected campaigns $(\mathbf{N}=\mathbf{2 0 0})$ & \\
Fundraising goal, total & $\$ 17,004,020$ \\
Donation received, total & $\$ 2,599,168$ \\
Fundraising goal, median (IQR) & $\$ 10,800(\$ 5,000-25,000)$ \\
Donation received, median (IQR) & $\$ 1,996(\$ 737-5562)$ \\
Amount per donation, median (IQR) & $\$ 52(\$ 39-82)$ \\
Donation amount per day, median (IQR) & $\$ 326(\$ 105-987)$ \\
Number of donors, median (IQR) & $33(15-96)$ \\
U.S. campaigns $(\boldsymbol{N}=\mathbf{9 2})$ & \\
Living expenses, lost wages, and food & $81(88.0 \%)$ \\
Medical supplies & $8(8.7 \%)$ \\
Hospitals and healthcare workers & $3(3.3 \%)$ \\
Non-U.S. campaigns $(\boldsymbol{N}=\mathbf{1 0 8})$ & \\
Hospitals and healthcare workers & $59(54.6 \%)$ \\
Medical supplies & $29(26.9 \%)$ \\
Living expenses, lost wages, and food & $18(16.7 \%)$ \\
Research & $2(1.9 \%)$ \\
Campaigns for Medical Supplies (N=37) & \\
U.S. campaigns & $8(21.6 \%)$ \\
PPE, including masks & $7(87.5 \%)$ \\
Critical care supplies and PPE & $0(0 \%)$ \\
Testing equipment & $1(12.5 \%)$ \\
European and other campaigns & $29(78.4 \%)$ \\
PPE, including masks & $14(48.3 \%)$ \\
Critical care supplies and PPE & $14(48.3 \%)$ \\
Testing equipment & $1(3.4 \%)$ \\
\hline
\end{tabular}

$I Q R$, interquartile range; U.S., United States; PPE, personal protective equipment

also providing real-time insights into global sentiment and local priorities.

Pawel Rajwa, MD PhD

Andrzej Paradysz, MD PhD

Jakub Wojnarowicz, BA

Medical University of Silesia,

Zabrze, Poland

\section{Philip Hopen, BS}

Data Science \& Clinical Analytics, New Century Health, Boston, MA, USA

Lin $\mathrm{Mu}, \mathrm{BS}$

Cary P. Gross, MD

Michael S. Leapman, MD

Yale University School of Medicine, New Haven, CT, USA

Corresponding Author: Michael S. Leapman, MD; Yale University School of Medicine New Haven, CT, USA (e-mail: michael.leapman@yale.edu).

\section{Compliance with Ethical Standards:}

Conflict of Interest: The authors declare that they do not have a conflict of interest.

\section{REFERENCES}

1. WHO. Coronavirus disease 2019 (COVID-19) Situation Report - 442020. Available from: https://www.who.int/docs/default-source/coronaviruse/ situation-reports/20200304-sitrep-44-covid-19.pdf?sfvrsn=783b4c9d_6.

2. Jernigan D. Update: Public Health Response to the Coronavirus Disease 2019 Outbreak - United States, February 24, 2020. MMWR Morbidity and mortality weekly report. 2020;69:216-9. doi: https://doi.org/10. 15585/mmwr.mm6908e1.

3. Cohen AJ, Brody H, Patino G, Ndoye M, Liaw A, Butler C, et al. Use of an Online Crowdfunding Platform for Unmet Financial Obligations in Cancer Care. JAMA Intern Med. 2019. doi: https://doi.org/10.1001/jamainternmed.2019.3330.

4. Organization WH. Novel Coronavirus (COVID-19) Situation Dashboard. Available from: https://experience.arcgis.com/experience/ 685d0ace521648f8a5beeeeelb9125cd.

5. Onder G, Rezza G, Brusaferro S. Case-Fatality Rate and Characteristics of Patients Dying in Relation to COVID-19 in Italy. Jama. 2020. doi: https:// doi.org/10.1001/jama.2020.4683.

6. Adams JG, Walls RM. Supporting the Health Care Workforce During the COVID-19 Global Epidemic. Jama. 2020. doi: https://doi.org/10.1001/ jama.2020.3972.

Publisher's Note: Springer Nature remains neutral with regard to jurisdictional claims in published maps and institutional affiliations. 